OPEN ACCESS

Edited by:

Emeline Tabouret,

Aix Marseille Université, France

Reviewed by:

Alireza Mansouri,

Pennsylvania State University (PSU),

United States

Tara H. W. Dobson,

University of Texas MD Anderson

Cancer Center, United States

${ }^{*}$ Correspondence:

Haiyun Wang

why819@126.com

Specialty section:

This article was submitted to

Neuro-Oncology and

Neurosurgical Oncology,

a section of the journal

Frontiers in Oncology

Received: 03 August 2020

Accepted: 26 October 2020

Published: 24 November 2020

Citation:

Yang C, Xia Z, Li T, Chen Y, Zhao $M$, Sun $Y$, Ma J, Wu Y, Wang $X$, Wang $P$ and Wang $H$ (2020) Antioxidant Effect

of Propofol in Gliomas and its

Association With Divalent

Metal Transporter 1.

Front. Oncol. 10:590931.

doi: 10.3389/fonc.2020.590931

\section{Antioxidant Effect of Propofol in Gliomas and Its Association With Divalent Metal Transporter 1}

\author{
Chenyi Yang ${ }^{1,2}$, Zhengyuan Xia ${ }^{3}$, Tang $L_{i}^{1,2}$, Yimeng Chen ${ }^{1,2}$, Mingshu Zhao ${ }^{1,2}$, Yi Sun ${ }^{1,2}$, \\ $\mathrm{Ji} \mathrm{Ma}{ }^{1,2}$, Yi Wu ${ }^{1,2}$, Xinyue Wang ${ }^{1,2}$, Peng Wang ${ }^{2}$ and Haiyun Wang ${ }^{1,2 *}$ \\ ${ }^{1}$ Department of Anesthesiology, The Third Central Hospital of Tianiin, Nankai University Affinity the Third Central Hospital, \\ The Third Central Clinical College of Tianjin Medical University, Tianjin, China, 2 Tianjin Key Laboratory of Extracorporeal Life \\ Support for Critical Diseases, Artificial Cell Engineering Technology Research Center, Tianjin Institute of Hepatobiliary Disease, \\ Tianjin, China, ${ }^{3}$ Department of Anesthesiology, The University of Hong Kong, Hong Kong, China
}

Background: Oxidative stress enhances tumor invasion and metastasis in brain cancer. The activation of divalent metal transporter 1 (DMT1), which is regulated by glutamate receptors, can result in the increase of oxidative stress and risk of cancer development. Propofol, an anesthetic with antioxidant capacity, has been shown to decrease oxidative stress in several different types of cancer. However, the underlying mechanism remains unclear. Therefore, the present study aimed to elucidate the mechanism underlying the suppression of oxidative stress in glioma cells by propofol. It was hypothesized that propofol may inhibit oxidative stress in gliomas via suppressing $\mathrm{Ca}^{2+}$-permeable $\alpha$-amino3-hydroxyl-5-methylisoxazole-4-propionic acid (AMPA) receptor (CPAR)-DMT1 signaling.

Methods: Male Wistar rats with C6 gliomas, which were established by intracranial injection of C6 glioma cells, were either treated with propofol or not for $6 \mathrm{~h}$ before being sacrificed. The levels of AMPA receptor subunit GluR2 and DMT1 protein expression were assessed using western blotting. The association between CPARs and DMT1 was confirmed in vitro using the AMPA receptor activator ( $R, S)-A M P A$. Glutathione and reactive oxygen species assay kits were used to evaluate tumor oxidative stress. The effect of propofol on glioma proliferation was evaluated by determining tumor weight, cell cycles and a growth curve.

Results: Propofol infusion at either 20 or $40 \mathrm{mg} / \mathrm{kg}^{-1} / \mathrm{h}^{-1}$ increased GluR2 levels and downregulated DMT1 expression as well as glutathione content markedly in the periphery compared with that in the glioma core. The in vitro results revealed that (R, S)-AMPA increased DMT1 expression and reactive oxygen species levels, which were partly reversed by propofol treatment.

Conclusion: Propofol regulated DMT1 expression by modulating CPARs, resulting in the inhibition of tumor oxidative stress and glioma growth. The present study provides evidence for optimizing the selection of anesthetic drugs in perioperative management and prognosis of patients with glioma.

Keywords: glioma, propofol, divalent metal transporter 1, $\alpha$-amino-3-hydroxy-5-methylisoxazole-4-propionic acid receptor, oxidative stress 


\section{INTRODUCTION}

Of tumors in the central nervous system, $>70 \%$ are gliomas, originating from astrocytes, oligodendrocytes and ependymal cells (1). The most common and fatal histological type is glioblastoma, which has a 5 -year survival rate $<5 \%$ in residents of England between 2007 and 2011 (2). An increasing number of studies have revealed that improper selection of anesthetics or anesthesia can adversely affect the prognosis of patients with glioma $(3,4)$. Therefore, optimizing the selection of anesthetic drugs in perioperative management has significant implications in the habilitation of patients with glioma. Propofol is widely used in clinical practice for intraoperative general anesthesia and postoperative sedation. Large amounts of evidence have confirmed that propofol inhibit the proliferation, invasion and migration, and facilitate apoptosis of tumor cells of various tissue origins, such as lung, gastrointestinal tract, pancreas, ovarian and cervical cancer (5-9). In addition, evidence has confirmed that propofol exhibits anti-oxidant capacity in various oxidative stress-induced diseases, such as Parkinson's disease and myocardial, lung and hepatic ischemic/reperfusion injuries (10-14). However, the mechanism underlying the effect of propofol in tumors, particularly gliomas, remains largely unknown.

$\alpha$-amino-3-hydroxy-5-methylisoxazole-4-propionic acid (AMPA) receptors combine with glutamate to mediate fast neurotransmission in excitatory synapses. AMPA receptors are also expressed in glial cells possessing the GluR2 subunit, which exhibits little $\mathrm{Ca}^{2+}$ permeability (15). However, AMPA receptors in glioma cells lacking the GluR2 subunit exhibit high $\mathrm{Ca}^{2+}$ permeability and are known as $\mathrm{Ca}^{2+}$-permeable AMPA receptors (CPARs) $(16,17)$. Researchers found that CPARs induce the proliferation and migration of human glioblastoma cells (18). In a neuron study, $\mathrm{N}$-methyl-D-aspartic acid (NMDA)-type glutamate receptors, which are expressed at low levels in glioma cells, were found to regulate the expression of the iron transporter, divalent metal transporter 1 (DMT1) (19). DMT1 is the main protein that transports iron into cells during iron metabolism (20). The expression of DMT1 is closely associated with the intracellular iron content, whose excess levels contribute to oxidative stress and protein aggregation, resulting in neuronal death (21). Furthermore, DMT1 overexpression increases reactive oxygen species (ROS) levels (22). ROS generated by tumors are directly involved in malignant transformation, and oxidative stress plays a key role in tumor progression and angiogenesis (23).

An in vitro study illustrated that the functional NMDA receptors are lost in membranes of glioma cells, while CPAR (without GluR2 subunits) expression is increased and eventually becomes the major glutamate receptor that mediate $\mathrm{Ca}^{2+}$ influx (24). Thus, the present study hypothesized that CPARs may be involved in the upstream regulation of DMT1. It has previously

Abbreviations: AMPA, $\alpha$-amino-3-hydroxy-5-methylisoxazole-4-propionic acid; CPARs, $\mathrm{Ca}^{2+}$-permeable AMPA receptors; CSF, cerebrospinal fluid; DMT1, divalent metal transporter 1; EAAT, excitatory amino acid transporters; FBS, fetal bovine serum; GSH, glutathione; ICUs, intensive care units; IRE, ironresponse element; NMDA, N-methyl-D-aspartic acid receptor; ROS, reactive oxygen species. been demonstrated that propofol downregulated CPAR expression in cerebral ischemia/reperfusion injury and conferred neuroprotective effects (25). The present study aimed to elucidate the mechanism underlying the suppression of oxidative stress in gliomas by propofol and to investigate whether propofol affects DMT1 expression by modifying CPARs and consequently influences the tumor redox status.

\section{MATERIALS AND METHODS}

\section{In Vivo Experiments}

\section{Animals}

All animal experiments were approved by the Ethics Committee of Experimental Animals of Tianjin Medical University. A total of 96 male Wistar rats (weight, 250-300 g; age, 7-8 weeks) were provided by the China Academy of Military Medical Science and cared for according to the Guide for the Care and Use of Laboratory Animals (26). Before the experiments, the rats were anesthetized with intraperitoneal injections of $1 \%$ pentobarbital $\left(40 \mathrm{mg} / \mathrm{kg}^{-1}\right)$.

\section{Cell Lines}

The rat C6 glioma cells (C6 cells) were provided by Dr Zhuo Yang (Medical College, Nankai University, Tianjin, China). After resuscitation, the cells were incubated at $37^{\circ} \mathrm{C}$ in a $5 \% \mathrm{CO}_{2}$ incubator and cultured in DMEM (high glucose; HyClone; Cytiva) containing 10\% FBS (Biological Industries) and 1\% antibiotic-antimitotic solution. The medium was changed daily using $75 \mathrm{~cm}^{2}$ culture flasks, passaged at least once until the logarithmic growth phase was reached, and prepared for further experiments.

For the in vivo tumor implantation, the passaged cells were washed with PBS and digested with 0.25\% trypsin in DMEM for digestion. The supernatant was discarded after centrifugation (1000 rpm for $5 \mathrm{~min}$ at $22^{\circ} \mathrm{C}$ ), and the cells were suspended in PBS to a final concentration of $10^{6}$ cells $/ 10 \mu$ l.

\section{Experimental Procedure}

The rats were randomly divided into four groups: Sham (S; n=24 per group); glioma ( $\mathrm{G} ; \mathrm{n}=24$ per group); and propofol 20 and 40 $\mathrm{mg} / \mathrm{kg}^{-1} / \mathrm{h}^{-1}$ (P1 and $\mathrm{P} 2$, respectively; $\mathrm{n}=24$ per group) groups. After receiving anesthesia, the rats were placed in a stereotactic head frame (David Kopf Instruments), and craniotomy was performed. The glioma model was then established in all groups, except for the $\mathrm{S}$ group, using stereotactic implantation of C6 glioma cells into the right caudate nucleus $(27,28)$. On the 10th day after model establishment, propofol was infused intravenously at two doses at a rate of 20 and $40 \mathrm{mg} / \mathrm{kg}^{-1} / \mathrm{h}^{-1}$ in groups P1 and P2, respectively, using a syringe pump for $6 \mathrm{~h}$. After 8 days, hematoxylin and eosin (H\&E) staining ( $n=6 /$ group) was performed and the glioma weight was measured $(n=6 /$ group). GluR2 and DMT1 expression was detected using western blotting ( $\mathrm{n}=6 /$ group) in the core and $2-\mathrm{mm}$ diameter periphery of the tumors. Cerebrospinal fluid (CSF) was collected to determine the glutathione (GSH) content. Propofol was 
purchased from AstraZeneca Plc. The 60-day survival rate was investigated every day after propofol treatment ( $n=10$ /group). The tumor volume was monitored weekly with MRI for 60 days. Animals were euthanized with pentobarbital $\left(150 \mathrm{mg} / \mathrm{kg}^{-1}\right)$ before the study endpoint, which were: i) If the tumor size exceeded $13 \mathrm{~mm}$ in diameter; ii) the animal showed excessive weight loss (20\% of body weight in a week), or iii) if the rat showed physiological signs of suffering (29).

\section{Rat C6 Glioma Model}

The procedure was performed $3 \mathrm{~mm}$ to the right of the midline and $1 \mathrm{~mm}$ anterior to the coronal suture. A total of $10 \mu 10^{6}$ glioma cells was implanted stereotactically into the caudate nucleus $5 \mathrm{~mm}$ below the drill hole, which was subsequently sealed using bone wax, and the scalp was closed with an intermittent suture $(27,28)$.

\section{Physiological Variables}

For blood pressure measurement and sampling of arterial blood gases, the present study inserted polyethylene catheters into the right femoral artery. Body temperature was monitored with a rectal probe and was maintained at $37 \pm 0.5^{\circ} \mathrm{C}$ using lamps. Physiological variables (mean arterial blood pressure, temperature and arterial blood gases) were measured before propofol treatment and $6 \mathrm{~h}$ after infusion.

\section{Histological Observation}

On the 18th day after the model was established, the rats were anesthetized and then euthanized with pentobarbital, followed by perfusion with formalin. The brains were subsequently removed and the weight of the fresh tumors was measured, followed by fixation in $10 \%$ formalin at a room temperature (RT) of $20 \pm 2^{\circ} \mathrm{C}$ for 1 day. Coronal sections were cut at the level of the implanted tumor. The tissue blocks were paraffin-embedded and sectioned to obtain $7-\mu \mathrm{m}$ thick slices, and then subjected to $\mathrm{H} \& \mathrm{E}$ staining. Glioma shape, tumor invasion range, necrosis and cellular arrangement were subsequently assessed.

\section{Western Blotting}

Tissues from the tumor core, 2-mm diameter tumor periphery of the tumor core and the ipsilateral hemisphere tissue from group $\mathrm{S}$, were collected on day 18 after the model was established. Tissues were homogenized in lysis buffer $\left(50 \mathrm{mmol} / \mathrm{l}^{-1}\right.$ Tris- $\mathrm{HCl}$ $\mathrm{pH}$ 6.8, $150 \mathrm{mmol} / \mathrm{l}^{-1} \mathrm{NaCl}, 5 \mathrm{mmol} / \mathrm{l}^{-1}$ EDTA, 0.5\% sodium deoxycholate, $0.5 \% \mathrm{NP}-40$ and protease inhibitor cocktail) and centrifuged $\left(12,000 \mathrm{rpm}\right.$ for $30 \mathrm{~min}$ at $\left.4^{\circ} \mathrm{C}\right)$. For measuring GluR2 and DMT1 expression, a membrane protein extraction kit (APeXBIO Technology LLC) was used to isolate membrane proteins. Aliquots of the supernatant containing $50 \mu \mathrm{g}$ protein were separated using $12 \%$ SDS-PAGE and immunoblotted onto polyvinylidene fluoride membranes. Then, the residual binding sites on the membrane were blocked by $5 \%$ skimmed milk powder for $1 \mathrm{~h}$ at RT. The membranes were incubated with primary antibodies (anti-GluR2 or anti-DMT1; both 1:1,000; both from Abcam; anti-GADPH, 1:7,000, ProteinTech Group, Inc.) for a night at $4^{\circ} \mathrm{C}$. They were then incubated with the secondary antibodies (1:5,000; KPL, Inc.) for $1 \mathrm{~h}$ at RT. Each step was followed by washing with tris-buffered saline (TBS) plus Tween-20 (20 mM Tris, $150 \mathrm{mM} \mathrm{NaCl}$ and 0.1\% Tween-20) 5 times for $5 \mathrm{~min}$ each time. Bands were visualized by exposing blots to $\mathrm{x}$-ray film after incubation with freshly made chemiluminescent reagent (EMD Millipore), and then quantitatively analyzed using ImageJ software version 1.0 (National Institutes of Health) in a blinded fashion.

\section{GSH Determination in CSF}

Each rat was anesthetized and placed in the stereotaxic frame. The skin was prepared and an incision was made along the midline over the occipital crest. After separating the tissues, an angiocath catheter was used to puncture the occipital foramen magnum, and $\sim 100 \mu$ of CSF was slowly withdrawn over a 2 min period. To remove blood cells, the CSF samples were centrifuged at $300 \mathrm{~g}$ for $2 \mathrm{~min}$. The GSH content was immediately determined using an enzymatic method with a commercial assay kit (Nanjing Jiancheng Bioengineering Institute) as described by Xia et al. (30).

\section{In Vitro Experiments \\ Experimental Process}

C6 cell density was $\sim 5 \times 10^{5}$ cells $/ \mathrm{ml}$ in the culture plate. For the in vitro study, the cells were divided into the following groups: Glioma (G); propofol 1.2 and $4.4 \mu \mathrm{g} / \mathrm{ml}^{-1}$ (P1 and P2, respectively); glioma treated with the AMPA receptor activator $(\mathrm{R}, \mathrm{S})$-AMPA $(100 \mu \mathrm{M}, \mathrm{A}+\mathrm{G}) ; \mathrm{A}+\mathrm{P} 1$; and $\mathrm{A}+\mathrm{P} 2$. The cells were passaged for $24 \mathrm{~h}$ until they reached $50 \%-70 \%$ confluency. They were then treated with $(\mathrm{R}, \mathrm{S})$-AMPA and propofol for $6 \mathrm{~h}$. The drug solutions were removed, and the cells were cultured for an additional $18 \mathrm{~h}$ to imitate the in vivo treatment. (R, S)-AMPA was purchased from Abcam. After the treatment, DMT1 expression and ROS levels were measured.

\section{Immunofluorescence Staining and ROS Level Assay}

The cells were grown on 6-well plates at a cell density of 30,000 cells/well and treated as previously described when cell confluence was up to $40 \%$ for live cell imaging. In the ROS assay, the cells were incubated in $25 \mu \mathrm{M}$ of the reagent from the ROS analysis kit (Abcam) for $30 \mathrm{~min}$ at $37^{\circ} \mathrm{C}$. The analysis of ROS levels was performed using a fluorescence microscope (magnification, $\times 200$; Olympus Corporation). Images were captured from random 6 fields for each group, and data were analyzed using ImageJ software. The mean grey intensity value of each cell was then calculated manually.

\section{Cell Cycle Analysis}

Glioma cells were harvested, washed twice with PBS, fixed with precooled $70 \%$ ethanol for a night at $4^{\circ} \mathrm{C}$, and stored at $-20^{\circ} \mathrm{C}$ for $12 \mathrm{~h}$. The cells were then resuspended in PBS containing $25 \mathrm{mg} / \mathrm{ml}^{-1}$ propidium iodide, $0.1 \%$ Triton, and $10 \mathrm{mg} / \mathrm{ml}^{-1}$ RNase; incubated for $30 \mathrm{~min}$ at RT in the dark; and analyzed by flow cytometry. All samples were assessed with FACScan system (BD Biosciences, USA). Data were analyzed using FlowJo version 10.0.7r2 (BD Biosciences). Measurements were repeated six times. 


\section{Cell Proliferation Curve}

The cells were digested and counted, $1 \times 10^{4}$ cells of each group were plated in each of the wells in a 12-well dish with complete medium. The 6 wells of cells from each group were randomly selected, trypsinized and counted manually every $24 \mathrm{~h}$ for 6 days.

\section{Statistical Analysis}

SPSS version 17.0 (SPSS Inc., USA) was used for the statistical analysis. Data are presented as the mean \pm standard deviation. The survival rates were calculated using the Kaplan-Meier method and analyzed by log-rank test, with Bonferroni corrected P-values $(\mathrm{P}<0.0083)$ for multiple comparisons. Statistical analysis of C6 glioma cells growth curve were performed using two-way analysis of variance (ANOVA). Other results were analyzed using one-way ANOVA. After one-way or two-way ANOVA, Tukey's multiple comparisons tests were applied. $\mathrm{P}<0.05$ was considered to indicate a statistically significant difference.

\section{RESULTS}

\section{Physiological Variables During the Experiment}

Physiological parameters, such as blood pressure, and temperature were closely monitored and controlled during the experimental period. There were no significant differences in these physiological parameters among rats in all groups during observation (before propofol treatment, and $6 \mathrm{~h}$ after infusion).

\section{Establishment of Rat C6 Glioma Model}

$\mathrm{H} \& \mathrm{E}$ staining revealed gliomas with irregular shapes and necrosis in the tumor core (Figure 1A). The necrotic regions were centrally coalesced, indicating a successfully established glioma model. Around the necrotic core region, typical palisading glioma cells were arranged in the peripheral part of the tumor. The tumor cells invaded the blood vessels (Figure 1B, arrowhead) up to the cerebral cortex, confirming that the rat C6 glioma model was successfully established on the right side of the caudate nucleus of the Wistar rats.

The glioma weight was analysed (Figure 1C). Compared with group $\mathrm{G}$, glioma weight was lower in both group P1 (G vs. P1: $0.42 \pm 0.06$ vs. $0.25 \pm 0.05 ; \mathrm{P}<0.001$ ) and group $\mathrm{P} 2$ ( $\mathrm{G}$ vs. $\mathrm{P} 2$ : $0.42 \pm 0.06$ vs. $0.25 \pm 0.04 ; \mathrm{P}<0.001)$, indicating that glioma growth was attenuated by propofol infusion. No differences between groups $\mathrm{P} 1$ and $\mathrm{P} 2$ were observed $(\mathrm{P}>0.05)$.

The survival rates were calculated using the Kaplan-Meier method and analyzed by the log-rank test. All the rats in group $S$ survived during the investigation. Compared with group $G$, the survival time was extended in groups $\mathrm{P} 1(\mathrm{P}=0.0092)$ and $\mathrm{P} 2$ $(\mathrm{P}=0.0356)$, suggesting that propofol infusion prolonged the survival time of C6 glioma rats, even though they were not significant after Bonferroni correction. Survival rates seemed

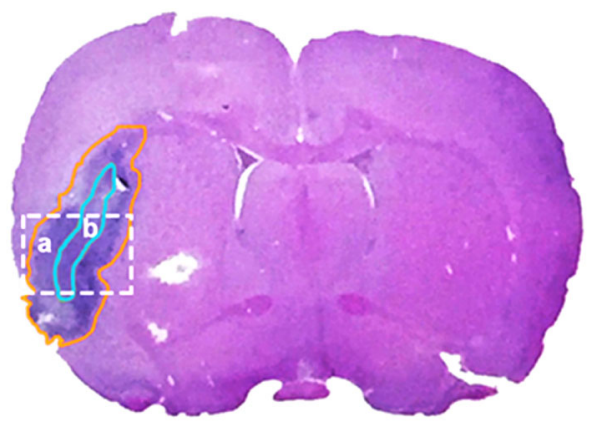

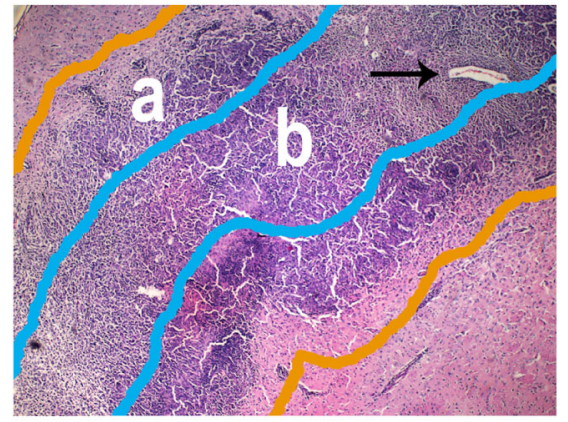

C

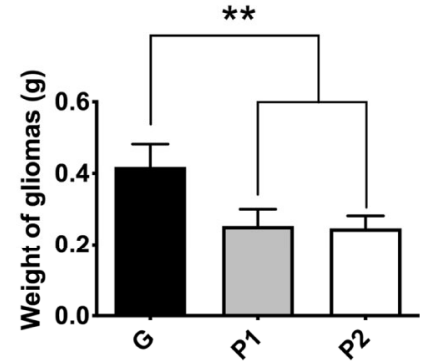

D

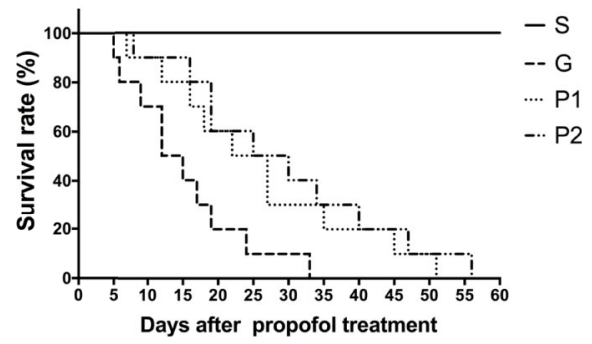

FIGURE 1 | Shape of rat C6 glioma was revealed by whole-brain slice H\&E staining, and 60-day survival curve was analyzed. (A, B) The shape of the glioma (a, gold circle) and tumor core (b, light blue circle) is shown using H\&E staining of a tumor tissue coronal slice. Glioma cells and vascular arrangement (arrowhead) observed using optical microscopy (magnification, $\times 40$ ). (C) On day 18 after establishing the C6 glioma model, the gliomas were removed from the rats and the weight of the fresh tumors was measured. Data are presented as the mean \pm standard deviation ( $n=6 /$ group). (D) The 60-day survival rate was investigated every day after propofol treatment ( $n=10 /$ group). ${ }^{*} P<0.01$. Groups: G, glioma; $P 1$ and $P 2$, propofol 20, and $40 \mathrm{mg} / \mathrm{kg}^{-1} / \mathrm{h}^{-1}$, respectively. H\&E, hematoxylin and eosin. 
higher in group $\mathrm{P} 2$ than in group $\mathrm{P} 1$, no statistical difference was observed between them $(\mathrm{P}>0.0083)$. These results suggest that propofol treatment can slightly delay the tumor progression of glioma rats (Figure 1D).

\section{Propofol Increased GluR2 Expression But Decreased DMT1 Expression and GSH Content In Vivo}

Western blotting revealed that GluR2 was expressed in both the 2-mm diameter periphery (Figure 2A) and tumor cores (Figure 2B) of the glioma, which was significantly decreased by tumor growth, compared with the expression levels observed in group $\mathrm{S}$ (S vs. G: $100 \pm 0$ vs. $33.56 \pm 1.96 ; \mathrm{P}<0.001$, and $\mathrm{S}$ vs. $\mathrm{P} 1: 100 \pm 0$ vs. $62.06 \pm 2.45 ; \mathrm{P}<0.001$, and $\mathrm{S}$ vs. $\mathrm{P} 2: 100 \pm 0$ vs. $67.86 \pm 2.03$; $\mathrm{P}<0.001$, in the periphery; $\mathrm{S}$ vs. $\mathrm{G}: 100 \pm 0$ vs. $21.00 \pm 1.31$; $\mathrm{P}<0.001$, and $\mathrm{S}$ vs. $\mathrm{P} 1: 100 \pm 0$ vs. $25.26 \pm 1.84 ; \mathrm{P}<0.001$, and $\mathrm{S}$ vs. $\mathrm{P} 2: 100 \pm 0$ vs. $25.50 \pm 3.43 ; \mathrm{P}<0.001$, in the core; Figure $2 \mathrm{C}$ ). Propofol administration sharply increased the expression of GluR2 in the periphery $(\mathrm{P}<0.01)$. However, no statistical differences were observed between groups $G$ and P1 or groups $\mathrm{G}$ and P2 in terms of GluR2 expression in the glioma core (Figure 2C). In addition, no significant difference existed between groups $\mathrm{P} 1$ and $\mathrm{P} 2$ in both areas. This finding suggests that propofol showed a greater effect in the tumor periphery than in the tumor core that was filled with glioma cells.

DMT1 expression results in both the $2-\mathrm{mm}$ diameter periphery (Figure 2D) and tumor core (Figure 2E) appeared to be opposite to that of GluR2 expression. DMT1 expression was higher in group $\mathrm{G}$ than in group S (S vs. G: $100 \pm 0$ vs. $535.50 \pm$ 14.69; $\mathrm{P}<0.001$, in the periphery; Figure 2F). Propofol reversed this change effectively ( $G$ vs. $P 1: 535.50 \pm 14.69$ vs. $280.61 \pm$ 13.18; $\mathrm{P}<0.001$, and $\mathrm{G}$ vs. $\mathrm{P} 2: 535.50 \pm 14.69$ vs. $247.13 \pm 13.02$; $\mathrm{P}<0.001$, in the periphery; Figure 2F), but the levels did not reach those in the periphery of group S. In summary, DMT1 was inversely proportional to GluR2. Considering that gliomas mostly express CPARs with no GluR2 subunit on the membrane, it can be suggested that CPARs may be associated with DMT1 expression.

The total GSH content significantly increased in groups G, P1, and $\mathrm{P} 2$ compared with group $\mathrm{S}$, which may reflect increased oxidative stress in the tumors ( $\mathrm{S}$ vs. G: $5.135 \pm 0.34$ vs. $10.62 \pm$ $0.16 ; \mathrm{P}<0.001, \mathrm{~S}$ vs. $\mathrm{P} 1: 5.135 \pm 0.34$ vs. $9.16 \pm 0.34 ; \mathrm{P}<0.001$, and $\mathrm{S}$ vs. $\mathrm{P} 2: 5.135 \pm 0.34$ vs. $8.32 \pm 0.30 ; \mathrm{P}<0.0011$; Figure $3 \mathrm{~A}$ ). Furthermore, the GSH/glutathione disulfide ratio increased following propofol infusion ( $G$ vs. P1: $4.75 \pm 0.19$ vs. $6.47 \pm$ $0.33 ; \mathrm{P}<0.01, \mathrm{G}$ vs. $\mathrm{P} 2: 4.75 \pm 0.19$ vs. $6.68 \pm 0.22 ; \mathrm{P}<0.001$; Figure 3B), which reflects the antioxidant effects of propofol.

\section{CPARs Promotes Oxidative Stress and Glioma Cell Proliferation by Upregulating DMT1 In Vitro}

The present study used (R, S)-AMPA to confirm the association between CPARs and DMT1. The in vitro experiments demonstrated changes in DMT1 expression in all groups (Figure 4A). The expression tendencies of cells in groups G, $\mathrm{P} 1$, and $\mathrm{P} 2$ both with and without $(\mathrm{R}, \mathrm{S})$-AMPA were similar to those observed in vivo. However, DMT1 expression was much higher in group P1 $(\mathrm{A}+\mathrm{P} 1)$ than in group P2 $(\mathrm{A}+\mathrm{P} 2)$, with significant differences ( $\mathrm{P} 1$ vs. $\mathrm{P} 2: 76.87 \pm 6.16$ vs. $33.88 \pm 5.97$; $\mathrm{P}<0.001$, and $\mathrm{A}+\mathrm{P} 1$ vs. $\mathrm{A}+\mathrm{P} 2: 105.90 \pm 5.64$ vs. $78.02 \pm 3.69$; $\mathrm{P}<0.01$; Figure 4B). After culturing with $(\mathrm{R}, \mathrm{S})$-AMPA, the DMT1 levels of the cells markedly increased and differed between groups $G$ and $(R, S)$-AMPA $(A)+G$, as well as between P1 and $\mathrm{A}+\mathrm{P} 1$ and between $\mathrm{P} 2$ and $\mathrm{A}+\mathrm{P} 2$ (G vs. A + G: $100 \pm 0$ vs. $146.11 \pm 6.51 ; \mathrm{P}<0.001$, $\mathrm{P} 1$ vs. $\mathrm{A}+\mathrm{P} 1: 76.87 \pm 6.16$ vs. $105.90 \pm 5.65 ; \mathrm{P}<0.01$; and $\mathrm{P} 2$ vs. $\mathrm{A}+\mathrm{P} 2: 33.88 \pm 5.9$ vs.
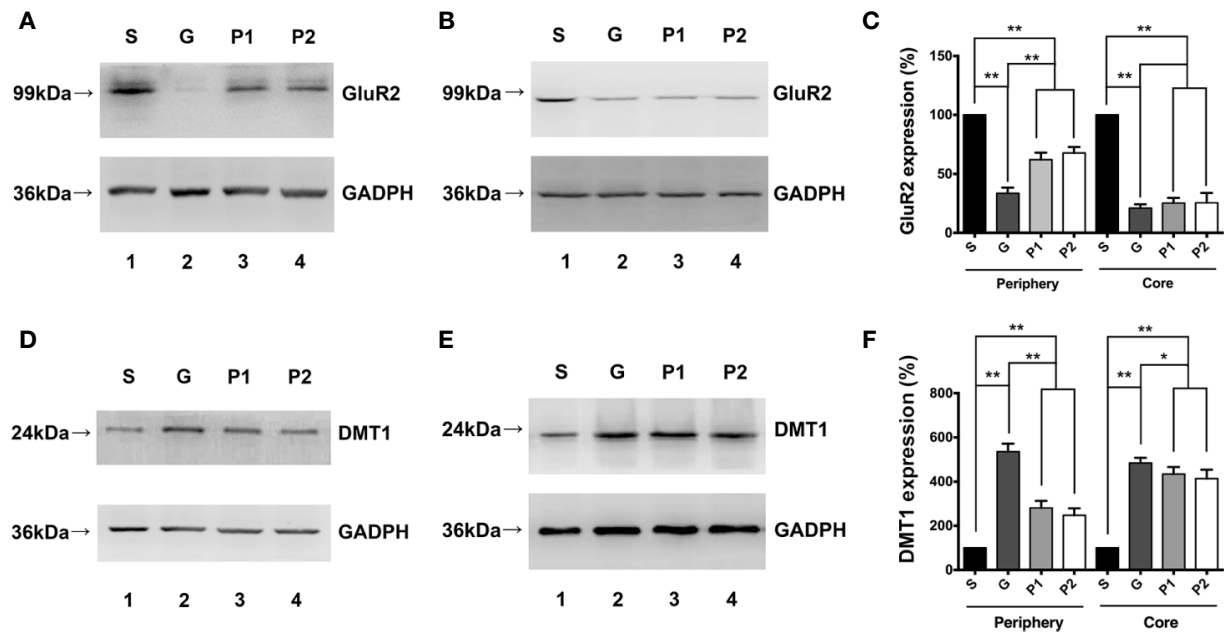

FIGURE 2 | Effects of propofol infusion on GluR2 and DMT1 in two areas 18 days after glioma model establishment. (A) Western blotting result showed expression of GluR2 in the 2-mm diameter periphery of the gliomas. (B) Expression of GluR2 in the core of the gliomas. (C) Quantification of GluR2 expression and comparison within periphery and core groups. (D) DMT1 expression in the 2-mm diameter periphery of gliomas. (E) DMT1 expression in the core of the gliomas. (F) Quantification of DMT1 expression and comparison within the periphery and core groups. Data are presented as the mean $\pm S D(n=6 / g r o u p)$. ${ }^{*}<0.05$ and ${ }^{* *} P<0.01$. Groups: $S$, sham; G, glioma; P1 and P2, propofol 20, and $40 \mathrm{mg} / \mathrm{kg}^{-1} / \mathrm{h}^{-1}$, respectively. DMT1, divalent metal transporter 1 . 

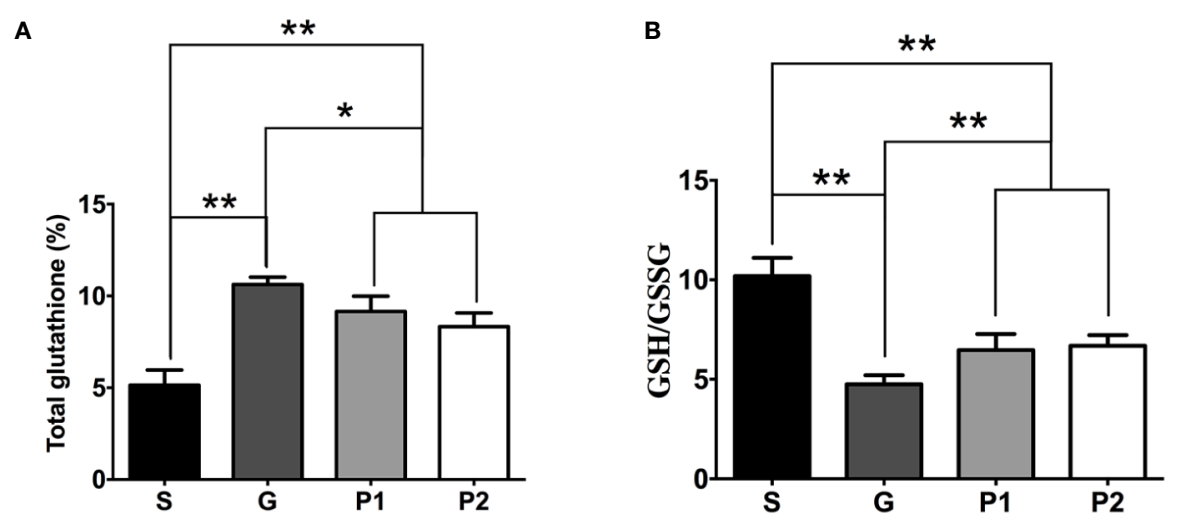

FIGURE 3 | On day 18 after C6 glioma model establishment, CSF was withdrawn from rats, and the total GSH content and GSH/GSSG ratio was determined. (A) Quantification of total GSH content in CSF ( $n=6 /$ group). (B) The analysis of GSH/GSSG ratio ( $n=6 /$ group). Data are presented as means \pm SD. ${ }^{\star} P<0.05$ and ${ }^{\star \star} P<$ 0.01. Groups: S, sham; G, glioma; P1 and P2, propofol 20, and 40 mg/ $\mathrm{kg}^{-1} / \mathrm{h}^{-1}$, respectively. CSF, cerebrospinal fluid; GSH, glutathione; GSSG, glutathione disulfide.

A

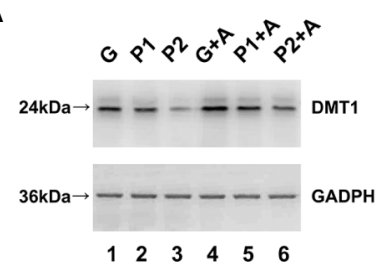

B

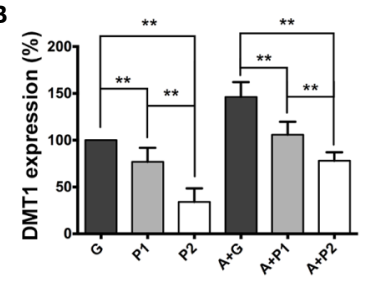

C

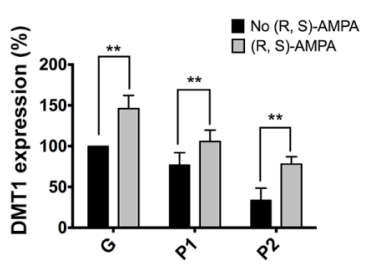

FIGURE $4 \mid(R, S)$-AMPA was incubated with tumor cells in vitro to confirm the relationship between Ca ${ }^{2+}$-permeable AMPA receptors and DMT1. (A) Western blotting result showed expression of DMT1 in glioma cells in vitro. (B, C) Quantification of DMT1 expression. Data are presented as mean \pm SD ( $\mathrm{n}=6 / \mathrm{group})$. ${ }^{\star \star} P<0.01$. Groups: S, sham; G, glioma; P1 and P2, propofol 1.2, and 4.4 $\mu \mathrm{g} / \mathrm{ml}^{-1}$, respectively; A, (R, S)-AMPA. AMPA, $\alpha$-amino-3-hydroxy-5-methyl-4isoxazolepropionic acid; DMT1, divalent metal transporter 1.

$78.02 \pm 3.69 ; \mathrm{P}<0.001$ ). Propofol reversed these increases (all $\mathrm{P}<0.01)$. However, the DMT1 levels did not reach the levels detected before CPAR activation (Figure 4C).

The ROS levels were directly proportional to DMT1 expression, as presented in Figure 5A. The administration of $(\mathrm{R}, \mathrm{S})$-AMPA exacerbated oxidative stress in glioma cells (Figure 5C), which may increase the demand for reducing agents and accelerate tumor metabolism and deterioration. Consistently, propofol inhibited ROS production ( $G$ vs. $P 1: 100 \pm 2.13$ vs. $84.83 \pm 3.14 ; \mathrm{P}<0.01$, and $\mathrm{G}$ vs. $\mathrm{P} 2: 100 \pm 2.13$ vs. $70.83 \pm 2.37$; $\mathrm{P}<0.01 ; \mathrm{A}+\mathrm{G}$ vs. $\mathrm{A}+\mathrm{P} 1: 119.28 \pm 4.01$ vs. $97.33 \pm 2.17 ; \mathrm{P}<0.001$, and $A+G$ vs. $A+P 2: 119.28 \pm 4.01$ vs. $79.83 \pm 2.09 ; \mathrm{P}<0.001$; Figure 5B), thereby preventing oxidative stress in gliomas.

A decrease in cell proliferation is often accompanied by changes in cell cycle progression. Therefore, the present study performed a cell cycle analysis and showed the administration of
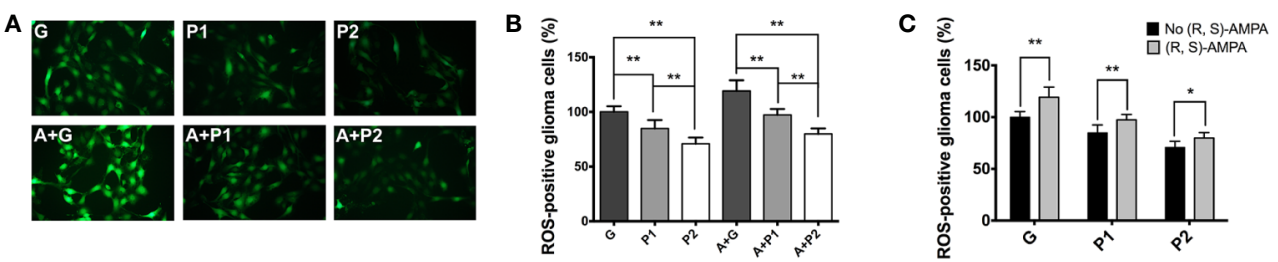

FIGURE 5 | Oxidative stress status was investigated using ROS assay. (A) Fluorescence image of cellular ROS productive levels (magnification, $\times 200)$. (B, C) Quantification of ROS levels in the gliomas. Data are presented as the mean $\pm S D$ ( $n=6 /$ group). ${ }^{*}<0.05$ and ${ }^{\star *} P<0.01$. Groups: $S$, sham; G, glioma; $\mathrm{P} 1$ and $P 2$, propofol 1.2, and $4.4 \mathrm{mg} / \mathrm{ml}^{-1}$, respectively; A, (R, S)- AMPA. ROS, reactive oxygen species; AMPA, $\alpha$-amino-3-hydroxyl-5-methyl-4-isoxazolepropionic acid. 
$(\mathrm{R}, \mathrm{S})$-AMPA increased tumor cell proliferation through escalating the numbers of cells in $S$ and $G_{2} / M$ phases, and reducing the numbers of cells in $G_{0} / G_{1}$ phase (Figure $6 C$ ). Cell cycle analysis also identified a marked increase induced by propofol in the numbers of cells arrested in the $G_{0} / G_{1}$ phase ( $G$ vs. $P 1: 59.17 \pm 0.35$ vs. $62.50 \pm 1.45 ; P<0.05$, and $G$ vs. $P 2$ : $59.17 \pm 0.35$ vs. $64.63 \pm 2.15 ; \mathrm{P}<0.05 ; \mathrm{A}+\mathrm{G}$ vs. $\mathrm{A}+\mathrm{P} 1: 54.33 \pm$ 0.91 vs. $56.73 \pm 0.35 ; \mathrm{P}<0.05$, and $\mathrm{A}+\mathrm{G}$ vs. $\mathrm{A}+\mathrm{P} 2: 54.33 \pm 0.91$ vs. $58.43 \pm 1.07 ; \mathrm{P}<0.05)$, while lowering the numbers of cells in $\mathrm{S}$ ( $G$ vs. $P 1: 18.30 \pm 1.06$ vs. $15.43 \pm 0.99 ; \mathrm{P}<0.05$, and $\mathrm{G}$ vs. $\mathrm{P} 2$ : $18.3 \pm 1.06$ vs. $11.37 \pm 0.80 ; \mathrm{P}<0.01 ; \mathrm{A}+\mathrm{G}$ vs. $\mathrm{A}+\mathrm{P} 1: 21.73 \pm$ 0.55 vs. $19.50 \pm 0.53 ; \mathrm{P}<0.01$, and $\mathrm{A}+\mathrm{G}$ vs. $\mathrm{A}+\mathrm{P} 2: 21.73 \pm 0.55$ vs. $18.97 \pm 0.65 ; P<0.05)$ and $G_{2} / M$ phases ( $G$ vs. $P 1: 14.57 \pm 0.31$ vs. $15.33 \pm 0.42 ; \mathrm{P}>0.05$, and $\mathrm{G}$ vs. $\mathrm{P} 2: 14.57 \pm 0.31$ vs. $18.57 \pm$ $0.47 ; \mathrm{P}<0.01 ; \mathrm{A}+\mathrm{G}$ vs. $\mathrm{A}+\mathrm{P} 1: 12.37 \pm 0.42$ vs. $17.27 \pm 1.50$; $\mathrm{P}<0.05$, and $\mathrm{A}+\mathrm{G}$ vs. $\mathrm{A}+\mathrm{P} 2: 12.37 \pm 0.42$ vs. $15.07 \pm 0.32$; $\mathrm{P}<0.05$ ), as compared with the $\mathrm{G}$ or $\mathrm{A}+\mathrm{G}$ group (Figures 6A, B). The present study then performed a C6 glioma cells proliferation assay. Proliferation curves revealed that propofol significantly decreased the proliferation rate $(\mathrm{G}$ vs. $\mathrm{P} 1$ : $\mathrm{P}<0.0001$, and $\mathrm{G}$ vs. $\mathrm{P} 2$ : $\mathrm{P}<0.0001 ; \mathrm{A}+\mathrm{G}$ vs. $\mathrm{A}+\mathrm{P} 1: \mathrm{P}=0.0003$, and $\mathrm{A}+\mathrm{G}$ vs. $\mathrm{A}+\mathrm{P} 2$ : $\mathrm{P}=0.0001$; Figure 6D). These data demonstrated that propofol maintained or prolonged C6 glioma cells in the $\mathrm{G}_{1}$-phase and, as a consequence, decreased tumor cell proliferation. The effect of propofol on glioma cell cycles and proliferation was consistent with that on glioma weight. Altogether, the in vitro results in the present study supported the in vivo results, which suggested that propofol serves as a tumor suppressor in glioma.

\section{DISCUSSION}

The present study aimed to elucidate the mechanism underlying the suppression of oxidative stress in gliomas by propofol and revealed that the effect of propofol on glioma cell cycles and proliferation was consistent with its effects on the 60-day survival rate. Taken together, the in vitro results of the present study supported the in vivo results, indicating that propofol may serve as a tumor suppressor in gliomas. Furthermore, propofol increased GluR2 and decreased glioma weight as well as DMT1 expression, with the effects being more apparent in the tumor periphery than in the core. Propofol decreased the GSH content in CSF, which may be a consequence of inhibition of oxidative stress in gliomas by propofol.

DMT1 is an iron importer protein responsible for ferrous iron influx. It is regulated by NMDA receptors in neurons (19). However, NMDA receptor expression in glioma cells is low. CPARs are vital glutamate receptors that are $\mathrm{Ca}^{2+}$-permeable. Thus, the present study surmised that CPARs may be involved in the upstream regulation of DMT1. To confirm this hypothesis, the present study performed in vitro experiments using $(\mathrm{R}, \mathrm{S})$ AMPA, a CPAR activator. The in vitro findings supported the hypothesis, as treatment with $(\mathrm{R}, \mathrm{S})$-AMPA increased DMT1 expression following CPAR expression upregulation, suggesting that CPARs may be involved in the upstream regulation of DMT1 in glioma cells. Yet propofol decreased DMT1 expression and tumor cell proliferation, which suggested that propofol partly reversed the effects of $(\mathrm{R}, \mathrm{S})$-AMPA. In addition,

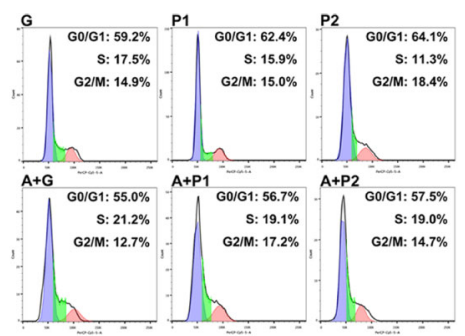

C

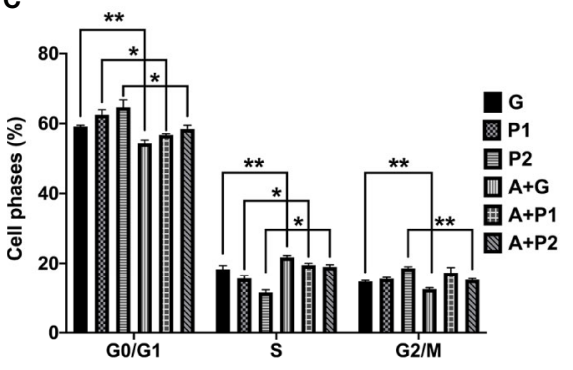

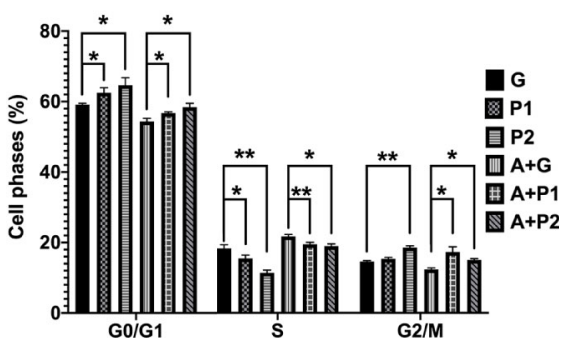

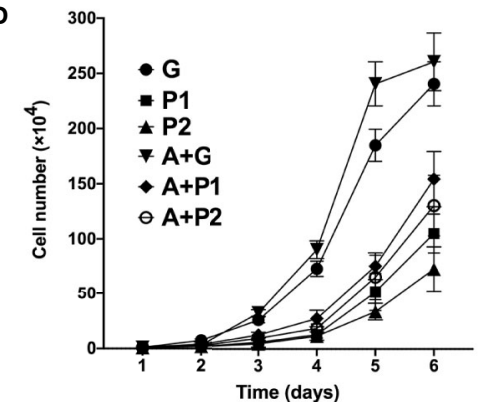

FIGURE 6 | It was revealed that propofol suppressed proliferation and cell cycle progression of glioma cells. (A-C) Cell cycle analysis of C6 glioma cells transduced with propofol or (R, S)-AMPA and analyzed by flow cytometry. (D) For the cell proliferation assay, 6 wells of cells from each group were randomly selected, digested and counted every $24 \mathrm{~h}$ for 6 days. Data are presented as the mean $\pm S D$ ( $n=6 /$ group). ${ }^{*} P<0.05$ and ${ }^{\star \star} P<0.01$. Groups: $S$, sham; $G$, glioma; $P 1$ and $P 2$, propofol 1.2 , and $4.4 \mu \mathrm{g} / \mathrm{ml}^{-1}$, respectively; A, (R, S)- AMPA. 
immunofluorescence staining results showed that ROS production was significantly increased in group $G$, while propofol lowered the tumor ROS level. In a previous study, pancreatic $\beta$-cell iron depletion with two iron chelators and DMT1 deletion by both siRNA and transgenic approaches decreased IL- $1 \beta$-induced ROS production and $\beta$-cell apoptosis in vitro, demonstrating the association between DMT1 and ROS (31). In line with these findings, the present study further demonstrated that propofol decreased ROS in tumors via regulation of DMT1. Previous published works demonstrating the antitumor effect of propofol in glioma were mainly based on in vitro studies, illustrated that propofol suppresses proliferation and invasion of glioma cells by upregulating microRNA-218 expression, inhibiting Wnt signaling or blocking the PI3K/Akt pathway through miR-206/ROCK1 axis (32-34). The present study revealed propofol anti-tumor effect from the perspective of oxidative stress inhibition in glioma cells through regulating DMT1 expression by modifying CPARs. Despite the lack of intracellular $\mathrm{Ca}^{2+}$ and $\mathrm{Fe}^{2+}$ tests, which is a limitation of the present study, to the best of our knowledge, the present study is the first to show that propofol decreases oxidative stress via a novel mechanism of DMT1 regulation.

The GSH content in the CSF and the cellular ROS production were significantly increased in group G, while propofol lowered tumor GSH and ROS levels. The expression and activity of glutamate transporters [excitatory amino acid transporters (EAAT) 1 and EAAT2] have been reported to be significantly decreased in both glioma cell lines and fresh glioma tissues (the ability to transport glutamate was only $1 / 100$ in the physiological state) (35). Furthermore, the cystine-glutamate antiporter $\left(x_{c}^{-}\right.$ system) activity increased (glutamate released was three times higher than the normal levels) (35). System $x_{c}^{-}$releases large amounts of glutamate, which is important for promoting glioma growth and for maintaining its invasiveness (36). Hypoxia usually occurs in gliomas due to its excessive growth and metabolism, while energy is mainly generated by anaerobic glycolysis, leading to intense generation of ROS. The elimination of intracellular ROS primarily relies on GSH, which is synthesized from cysteine. The accumulation of cellular ROS would thus enhance system $x_{c}^{-}$activity to meet the requirement for GSH (37). It has been reported that extracellular glutamate increased with $x_{c}^{-}$upregulation, which in turn induces $\mathrm{Ca}^{2+}$ influx through CPARs, and the latter can then induce calcium overload in the mitochondria and produce abundant ROS $(38,39)$. Sato et al. (40) recently demonstrated that the ferroptosis inducer erastin irreversibly inhibits system $x_{c}^{-}$ leading to cysteine starvation, glutathione depletion, and consequently ferroptotic cell death, and efficiently kills human tumor cells without killing their isogenic normal cell counterparts. Ferroptosis refers to a novel iron-dependent form of regulated necrotic cell death (41). Hence, iron metabolism and system $x_{c}^{-}$ have recently emerged as potential targets in the context of cancer therapy. It was previously observed that propofol decreased CPAR expression, which inhibits calcium transport to reduce ischemia/ reperfusion injury (25). It was recently revealed that propofol could inhibit CPARs and decrease viability, invasiveness and migration of C6 glioma cells (42). The results of the present study show that propofol inhibits oxidative stress and DMT1 expression and eventually downregulates GSH and ROS production, which disrupts the energy supply required for tumor growth and metabolism (Figure 7).

In the in vivo experiments in the present study, propofol doses of 20 and $40 \mathrm{mg} / \mathrm{kg}^{-1} / \mathrm{h}^{-1}$, which corresponded to 1.2 and $4.4 \mu \mathrm{g} / \mathrm{ml}^{-1}$ of propofol for incubating cells in vitro, were selected and determined based on the following findings. In previous research on ischemia/reperfusion injury, compared with propofol infusion rate of $35 \mathrm{mg} / \mathrm{kg}^{-1} / \mathrm{h}^{-1}$, propofol at doses of 10 and $20 \mathrm{mg} / \mathrm{kg}^{-1} / \mathrm{h}^{-1}$ were found to confer improved protective effects against brain functional injury and ischemia/reperfusion injury, which had no statistic difference between them (25). In addition, using $10 \mathrm{mg} / \mathrm{kg}^{-1} / \mathrm{h}^{-1}$ propofol alone could barely maintain general anesthesia, let alone provide sedation to rats. Therefore, the present study selected the sub-anesthetic dose of $20 \mathrm{mg} / \mathrm{kg}^{-1} / \mathrm{h}^{-1}$ to continue the further studies. Logginidou et al. (43) reported that the corresponding estimated plasma
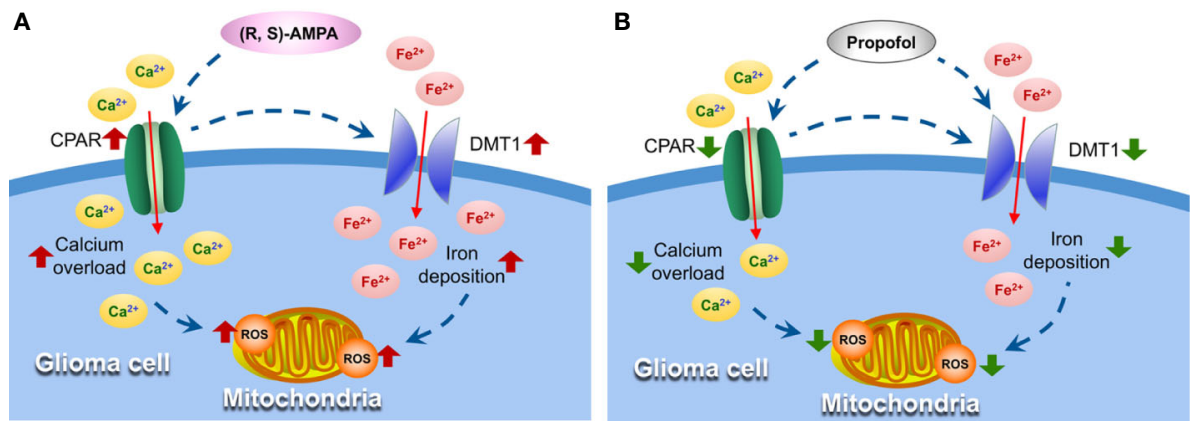

FIGURE 7 | Propofol suppresses oxidative stress in glioma cells by inhibiting DMT1 and CPAR expression. (A) AMPA receptor activator (R, S)-AMPA induces CPARs upregulation and $\mathrm{Ca}^{2+}$ influx, which can cause the excessive expression of DMT1, followed by increased ROS formation in mitochondria. (B) Propofol inhibits CPAR and DMT1 expression and eventually suppresses oxidative stress and tumor growth. DMT1, divalent metal transporter 1; AMPA, $\alpha$-amino-3-hydroxyl-5methyl-4-isoxazolepropionic acid; CPAR, $\mathrm{Ca}^{2+}$-permeable AMPA receptors; ROS, reactive oxygen species. 
concentration of propofol was $1.2 \mu \mathrm{g} / \mathrm{ml}^{-1}$ when the infusion rate was $20 \mathrm{mg} / \mathrm{kg}^{-1} / \mathrm{h}^{-1}$. Furthermore, the steady-state mean arterial blood propofol concentration for general anesthesia was $4.4 \mu \mathrm{g} /$ $\mathrm{ml}^{-1}$, when the infusion speed was $40 \mathrm{mg} / \mathrm{kg}^{-1} / \mathrm{h}^{-1}$ in vivo, which was selected for comparison $(43,44)$. Nevertheless, propofol at doses of 36 and $72 \mathrm{mg} / \mathrm{kg}^{-1} / \mathrm{h}^{-1}$ exacerbated brain injury, hindered post-traumatic neurogenesis, and increased the 28 day mortality after experimentally-induced trauma, which demonstrated that propofol brain protective effect was not dose-dependent (45). The present study revealed that propofol infusion rates of 20 and $40 \mathrm{mg} / \mathrm{kg}^{-1} / \mathrm{h}^{-1}$ caused different effects in gliomas, but led to no statistical differences in vivo. This observation could be explained by the interference of other factors in rats; however, the cell culture environment was less complex. Glioma cells were much more vulnerable to propofol than rats, and the increase in propofol dose in vitro may produce significant differences compared with a sub-dose. In addition, the follow-up study will continuously observe the long-term effects of propofol on tumors, since the effect of ROS on tumors may be neither constant nor unique (46).

\section{CONCLUSION}

In the present study, it was revealed that propofol regulates DMT1 expression by modifying CPARs, thereby inhibiting tumor oxidative stress and tumor growth. The findings of the present study suggested that perioperative propofol application may help achieve good quality of glioma prognosis, although clinical trials are needed to test this intriguing hypothesis, as various factors affected the condition of patients with glioma. In clinical studies, it is difficult to conclude whether any anesthetic at any certain dose has marked antitumor effects. However, from the perspective of anesthesiologists, it is necessary to minimize the risk of long-term metastasis and recurrence, and provide safe,

\section{REFERENCES}

1. Ostrom QT, Gittleman H, Fulop J, Liu M, Blanda R, Kromer C, et al. CBTRUS Statistical Report: Primary Brain and Central Nervous System Tumors Diagnosed in the United States in 2008-2012. Neuro-oncology (2015) 17: iv1-iv62. doi: 10.1093/neuonc/nov189

2. Brodbelt A, Greenberg D, Winters T, Williams M, Vernon S, Collins VP, et al. Glioblastoma in England: 2007-2011. Eur J Cancer (2015) 51:533-42. doi: 10.1016/ j.ejca.2014.12.014

3. Cata JP, Hagan KB, Bhavsar SD, Arunkumar R, Grasu R, Dang A, et al. The use of isoflurane and desflurane as inhalational agents for glioblastoma surgery. a survival analysis. J Clin Neurosci (2016) 35:82-7. doi: 10.1016/j.jocn.2016.10.006

4. Evans DR, Fowler-Williams C, Ma D. Is volatile anesthesia during cancer surgery likely to increase the metastatic risk? Int Anesthesiol Clin (2016) 54:92-107. doi: 10.1097/AIA.0000000000000115

5. Liu WZ, Liu N. Propofol inhibits lung cancer a549 cells growth and epithelialmesenchymal transition process by up-regulation of microrna-1284. Oncol Res (2018) 27:1-8. doi: 10.3727/096504018X15172738893959

6. Zheng X, Wang Y, Dong L, Zhao S, Wang L, Chen H, et al. Effects of propofolbased total intravenous anesthesia on gastric cancer: a retrospective study. Onco Targets Ther (2018) 11:1141-8. doi: 10.2147/OTT.S156792 comfortable and high-quality anesthesia management in patients with glioma.

\section{DATA AVAILABILITY STATEMENT}

The raw data supporting the conclusions of this article will be made available by the authors, without undue reservation.

\section{ETHICS STATEMENT}

The animal study was reviewed and approved by the Committee of Experimental Animals of Tianjin Medical University.

\section{AUTHOR CONTRIBUTIONS}

HW, ZX, and CY designed the present study. CY, TL, YC, XW, and PW performed the experiments. CY, MZ, YS, JM, and YW analyzed the data. CY, HW, and ZX wrote the article. All authors contributed to the article and approved the submitted version.

\section{FUNDING}

The present study was supported by grants from the National Natural Science Foundation of China (Grant No. 82071220), the Natural Science Foundation of Tianjin (Grant No. 20JCYBJC01290), the Tianjin Major Support Program of Science and Technology (Grant No. 18YFZCSY00530), the Tianjin Research Program of Application Foundation and Advanced Technology (Grant No. 15JCYBJC25600), and the Young Scholar Research Grant of Chinese Anesthesiologist Association (Grant No. 21800004).
7. Zeng J, Li YK, Quan FF, Zeng X, Chen CY, Zeng T, et al. Propofol-induced miR$125 \mathrm{a}-5 \mathrm{p}$ inhibits the proliferation and metastasis of ovarian cancer by suppressing LIN28B. Mol Med Rep (2020) 22:1507-17. doi: 10.3892/mmr.2020.11223

8. Li H, Lu Y, Pang Y, Li M, Cheng X, Chen J. Propofol enhances the cisplatininduced apoptosis on cervical cancer cells via EGFR/JAK2/STAT3 pathway. Biomed Pharmacother (2016) 86:324. doi: 10.1016/j.biopha.2016.12.036

9. Chen X, Wu Q, Li Y, Chen S, Zhu M, Miao C. Propofol attenuates pancreatic cancer malignant potential via inhibition of nmda receptor. Eur J Pharmacol (2016) 795:150-9. doi: 10.1016/j.ejphar.2016.12.017

10. Romuk E, Szczurek W, Nowak P, Skowron M, Prudel B, Hudziec E, et al. Effects of Propofol on Oxidative Stress Parameters in Selected Parts of the Brain in a Rat Model of Parkinson Disease. Postepy Hig Med Dosw (2016) 70:1441. doi: 10.5604/17322693.1227841

11. Xia Z, Huang Z, Ansley DM. Large-dose propofol during cardiopulmonary bypass decreases biochemical markers of myocardial injury in coronary surgery patients: a comparison with isoflurane. Anesth Analg (2006) 103:527-32. doi: 10.1213/01.ane.0000230612.29452.a6

12. Jin YC, Kim W, Ha YM, Shin IW, Sohn JT, Kim HJ, et al. Propofol limits rat myocardial ischemia and reperfusion injury with an associated reduction in apoptotic cell death in vivo. Vasc Pharmacol (2009) 50:71-7. doi: 10.1016/ j.vph.2008.10.002 
13. Balyasnikova IV, Visintine DJ, Gunnerson HB, Paisansathan C, Baughman VL, Minshall RD, et al. Propofol attenuates lung endothelial injury induced by ischemia-reperfusion and oxidative stress. Anesth Analg (2005) 100:929-36. doi: 10.1213/01.ANE.0000147707.49192.88

14. Bellanti F, Mirabella L, Mitarotonda D, Blonda M, Tamborra R, Cinnella G, et al. Propofol but not sevoflurane prevents mitochondrial dysfunction and oxidative stress by limiting HIF-1 $\alpha$ activation in hepatic ischemia/reperfusion injury. Free Radical Biol Med (2016) 96:323-33. doi: 10.1016/ j.freeradbiomed.2016.05.002

15. Lomeli H, Mosbacher J, Melcher T, Höger T, Geiger JR, Kuner T, et al. Control of kinetic properties of AMPA receptor channels by nuclear RNA editing. Science (1994) 266:1709-13. doi: 10.1126/science.7992055

16. Ishiuchi S, Tsuzuki K, Yoshida Y, Yamada N, Hagimura N, Okado H, et al. Blockage of $\mathrm{Ca}(2+)$-permeable ampa receptors suppresses migration and induces apoptosis in human glioblastoma cells. Nat Med (2002) 8:971-8. doi: $10.1038 / \mathrm{nm} 746$

17. Colman H, Zhang L, Sulman EP, McDonald JM, Shooshtari NL, Rivera A, et al. A multigene predictor of outcome in glioblastoma. Neuro-oncology (2010) 12:49-57. doi: 10.1093/neuonc/nop007

18. Ishiuchi S, Yoshida $\mathrm{Y}$, Sugawara $\mathrm{K}$, Aihara $\mathrm{M}$, Ohtani $\mathrm{T}$, Watanabe $\mathrm{T}$, et al. Ca2+-permeable AMPA receptors regulate growth of human glioblastoma via akt activation. J Neurosci (2007) 27:7987. doi: 10.1523/JNEUROSCI.218007.2007

19. White RS, Bhattacharya AK, Chen Y, Byrd M, McMullen MF, Siegel SJ, et al. Lysosomal iron modulates NMDA receptor-mediated excitation via small GTPase, Dexras1. Mol Brain (2016) 9:38. doi: 10.1186/s13041-016-0220-8

20. Li Y, Pan K, Chen L, Ning JL, Li X, Yang T, et al. Deferoxamine regulates neuroinflammation and iron homeostasis in a mouse model of postoperative cognitive dysfunction. J Neuroinflammation (2016) 13:268. doi: 10.1186/ s12974-016-0740-2

21. Howitt J, Putz U, Lackovic J, Doan A, Dorstyn L, Cheng H. Divalent Metal Transporter 1 (DMT1) Regulation by Ndfip 1 Prevents Metal Toxicity in Human Neurons. Proc Natl Acad Sci U S A (2009) 106:15489-94. doi: 10.1073/ pnas.0904880106

22. Wang XF, Cynader MS. Astrocytes provide cysteine to neurons by releasing glutathione. J Neurochem (2010) 74:1434-42. doi: 10.1046/j.14714159.2000.0741434.x

23. Chandel NS, Maltepe E, Goldwasser E, Mathieu CE, Simon MC, Schumacker PT. Mitochondrial reactive oxygen species trigger hypoxia-induced transcription. Proc Natl Acad Sci USA (1998) 95:11715-20. doi: 10.1073/ pnas.95.20.11715

24. Lyons SA, Chung WJ, Weaver AK, Ogunrinu T, Sontheimer H. Autocrine glutamate signaling promotes glioma cell invasion. Cancer Res (2007) 67:9463. doi: 10.1158/0008-5472.CAN-07-2034

25. Wang H, Luo M, Li C, Wang G. Propofol post-conditioning induced longterm neuroprotection and reduced internalization of AMPAR GluR2 subunit in a rat model of focal cerebral ischemia/reperfusion. J Neurochem (2011) 119:210-9. doi: 10.1111/j.1471-4159.2011.07400.x

26. The National Research Council. (US) Committee for the Update of the Guide for the Care and Use of Laboratory Animals. Guide for the Care and Use of Laboratory Animals. Eighth Edition. US: National Academies Press (2011).

27. Pu P, Liu XA, Cui J, Zhang Y. Inhibitory effect of antisense epidermal growth factor receptor RNA on the proliferation of rat C6 glioma cells in vitro and in vivo. J Neurosurg (2000) 92:132-9. doi: 10.3171/jns.2000.92.1.0132

28. Bouzier AK, Quesson B, Valeins H, Canioni P, Merle M. [1-(13)C]glucose metabolism in the tumoral and nontumoral cerebral tissue of a gliomabearing rat. J Neurochem (1999) 72:2445-55. doi: 10.1046/j.14714159.1999.0722445.x

29. Morton DB, Griffiths PH. Guidelines on the recognition of pain, distress and discomfort in experimental animals and an hypothesis for assessment. Vet Rec (1985) 116:431-6. doi: 10.1136/vr.116.16.431

30. Xia Z, Guo Z, Nagareddy PR, Yuen V, Yeung E, McNeill JH. Antioxidant Nacetylcysteine restores myocardial Mn-SOD activity and attenuates myocardial dysfunction in diabetic rats. Eur J Pharmacol (2006) 544:11825. doi: 10.1016/j.ejphar.2006.06.033

31. Hansen JB, Tonnesen MF, Madsen AN, Hagedorn PH, Friberg J, Grunnet LG. Divalent Metal Transporter 1 Regulates Iron-Mediated ROS and Pancreatic $\beta$
Cell Fate in Response to Cytokines. Cell Metab (2012) 16:449. doi: 10.1016/ j.cmet.2012.09.001

32. Xu J, Xu W, Zhu J. Propofol suppresses proliferation and invasion of glioma cells by upregulating microRNA-218 expression. Mol Med Rep (2015) 12:4815-20. doi: $10.3892 / \mathrm{mmr} .2015 .4014$

33. Xu W, Zheng J, Bie S, Kang L, Mao Q, Liu W, et al. Propofol inhibits Wnt signaling and exerts anticancer activity in glioma cells. Oncol Lett (2018) 16:402-8. doi: 10.3892/ol.2018.8606

34. Wang D, Yang T, Liu J, Liu Y, Xing N, He J, et al. Propofol Inhibits the Migration and Invasion of Glioma Cells by Blocking the PI3K/AKT Pathway Through miR-206/ROCK1 Axis. Onco Targets Ther (2020) 13:361-70. doi: $10.2147 / O T T . S 232601$

35. Bridges R, Lutgen V, Lobner D, Baker DA. Thinking outside the cleft to understand synaptic activity: contribution of the cystine-glutamate antiporter (System $\mathrm{Xc}^{-}$) to normal and pathological glutamatergic signaling. Pharmacol Rev (2012) 64:780-802. doi: 10.1124/pr.110.003889

36. Blecic S, Rynkowski M, De Witte O, Lefranc F. Glutamate and malignant gliomas, from epilepsia to biological aggressiveness: therapeutic implications. Bull Cancer (2013) 100:829-35. doi: 10.1684/bdc.2013.1781

37. Robert SM, Ogunrinu-Babarinde T, Holt KT, Sontheimer H. Role of glutamate transporters in redox homeostasis of the brain. Neurochem Int (2014) 73:181-91. doi: 10.1016/j.neuint.2014.01.001

38. Ekici M, Keim A, Rossler OG, Hohi M, Thiel G. Chromatin structure and expression of the AMPA receptor subunit Glur2 in human glioma cells: major regulatory role of REST and Sp1. J Cell Biochem (2012) 113:528-43. doi: $10.1002 /$ jcb. 23376

39. Wang K, Zhu X, Zhang K, Wu Z, Sun S, Zhou F, et al. Neuroprotective effect of puerarin on glutamate-induced cytotoxicity in differentiated Y-79 cells via inhibition of ROS generation and $\mathrm{Ca}(2+)$ influx. Int J Mol Sci (2016) 17:1109. doi: 10.3390/ijms17071109

40. Sato M, Kusumi R, Hamashima S, Kobayashi S, Sasaki S, Komiyama Y, et al. The ferroptosis inducer erastin irreversibly inhibits system xc- and synergizes with cisplatin to increase cisplatin's cytotoxicity in cancer cells. Sci Rep (2018) 8:968. doi: 10.1038/s41598-018-19213-4

41. Shen Z, Song J, Yung BC, Zhou Z, Wu A, Chen X. Emerging strategies of cancer therapy based on ferroptosis. Adv Mater (2018) 30:e1704007. doi: 10.1002/adma.201704007

42. Wang XY, Li YL, Wang HY, Zhu M, Guo D, Wang GL, et al. Propofol inhibits invasion and proliferation of $\mathrm{C} 6$ glioma cells by regulating the $\mathrm{Ca}^{2+}$ permeable AMPA receptor-system $x^{-}$pathway. Toxicol Vitro (2017) 44:57-65. doi: 10.1016/j.tiv.2017.06.026

43. Logginidou HG, Li BH, Li DP, Lohmann JS, Schuler HG, DiVittore NA, et al. Propofol suppresses the cortical somatosensory evoked potential in rats. Anesth Analg (2003) 97:1784-8. doi: 10.1213/01.ane.0000090318.16879.a8

44. Mahli A, Coskun D, Karaca GI, Akcali DT, Karabiyik L, Karadenizli Y. Targetcontrolled infusion of remifentanil with propofol or desflurane under bispectral index guidance: quality of anesthesia and recovery profile. $J$ Res Med Sci (2011) 16:611-20. doi: 10.2143/ACB.66.3.2062564

45. Thal SC, Timaru-Kast R, Wilde F, Merk P, Johnson F, Frauenknecht K, et al. Propofol impairs neurogenesis and neurologic recovery and increases mortality rate in adult rats after traumatic brain injury. Crit Care Med (2014) 42:129-41. doi: 10.1097/CCM.0b013e3182a639fd

46. Perillo B, Di Donato M, Pezone A, Di Zazzo E, Giovannelli P, Galasso G, et al. ROS in cancer therapy: the bright side of the moon. Exp Mol Med (2020) 52:192-203. doi: 10.1038/s12276-020-0384-2

Conflict of Interest: The authors declare that the research was conducted in the absence of any commercial or financial relationships that could be construed as a potential conflict of interest.

Copyright (c) 2020 Yang, Xia, Li, Chen, Zhao, Sun, Ma, Wu, Wang, Wang and Wang. This is an open-access article distributed under the terms of the Creative Commons Attribution License (CC BY). The use, distribution or reproduction in other forums is permitted, provided the original author(s) and the copyright owner(s) are credited and that the original publication in this journal is cited, in accordance with accepted academic practice. No use, distribution or reproduction is permitted which does not comply with these terms. 